\title{
Microanalysis of Hafnian Zircon
}

\author{
Chi Ma and George R. Rossman
}

Division of Geological and Planetary Sciences, California Institute of Technology, Pasadena, CA 91125

As revealed by FE-SEM and electron probe microanalysis, we report that hafnian zircon $(\mathrm{Zr}, \mathrm{Hf}) \mathrm{SiO}_{4}$ with $\mathrm{Hf} / \mathrm{Zr}$ atomic ratio up to1.0 is present in the famous Stewart pegmatite, Pala District, San Diego County, California. The Stewart mine, as part of the gem-bearing and rareelement-bearing granitic pegmatites in Southern California, has been mined for pink tourmaline and purple lepidolite for over a century ${ }^{1}$. Zircon is known to be one of the most important minerals for dating rocks and studying trace element geochemistry ${ }^{2}$. Hafnian zircon and hafnon $\left(\mathrm{HfSiO}_{4}\right)$ are rare in nature ${ }^{3}$. This investigation is to understand the occurrence, composition and genesis of hafnian zircon, which may insight as to how the Stewart pegmatite and various pink tourmalines formed.

Zircons from the Stewart pegmatite (specimens GRR2318 and GRR2319), occurring along with fine grained tourmaline (elbaite), lepidolite and muscovite as a trace accessory mineral (occupying less than 0.1 area\%), show irregular shapes and range in size from $20 \mu \mathrm{m}$ to $40 \mu \mathrm{m}$. BSE and CL imaging reveals the zircon texture with irregular internal zoning and irregular overgrowth (FIG. 1 and FIG. 2a \& 2b). None of zircons examined shows oscillatory zoning like those found in granites and many other pegmatites. Pores, inclusions of brabantite $\left[\mathrm{CaTh}\left(\mathrm{PO}_{4}\right)_{2}\right]$ and thorite $\left[(\mathrm{Th}, \mathrm{U}) \mathrm{SiO}_{4}\right]$, and altered patches at a micrometer scale are common in the primary domain of the Stewart zircons, where late overgrowths are smooth and inclusion-free. EBSD analysis shows that the zircon grains are single crystals despite their heterogeneous composition and overgrowth. The alteration patches do not have the zircon structure. The Stewart zircons are hafnian zircon with $\mathrm{HfO}_{2}$ up to $44 \mathrm{wt} \%$. The primary domain is always highly Hf-rich with $\mathrm{Hf} / \mathrm{Zr}$ ratios from 0.7 to 1.0 . Altered patches are likely hydrated zirconium hafnium silicates with high Th content. There are two stages of overgrowths; an early one (Type I) with $\mathrm{Hf} / \mathrm{Zr}=0.08 \sim 0.14$, and a late one (Type II) with $\mathrm{Hf} / \mathrm{Zr}=0.8 \sim 1.0$. Fig.2 shows a zircon crystal with Type I and Type II overgrowths.

Hafnium often is enriched in the rims of zircons of granitic pegmatites in the late stages of the pegmatite crystallization. However, hafnian zircon is an exception in this case. It is evident that the Stewart zircon underwent a complex growth history. Primary zircon formed by Hf-enriched pegmatite crystallization, then altered by Th-enriched fluid. Two overgrowths took place later with very different Hf-enriched recrystallizations.

\section{References}

[1] J. Fisher, Mineral. Record, 33 (2002) 363.

[2] P.W.O. Hoskin and R. Schaltegger, Reviews Mineral. Geochem., 53 (2003) 27-62.

[3] J.M. Correia et al., Contrib. Mineral. Petrol., 48 (1974) 73-80.

[4] This project is funded by the White Rose Foundation. The Caltech GPS Analytical Facility is supported in part by the MRSEC Program of the NSF under DMR-0080065. 


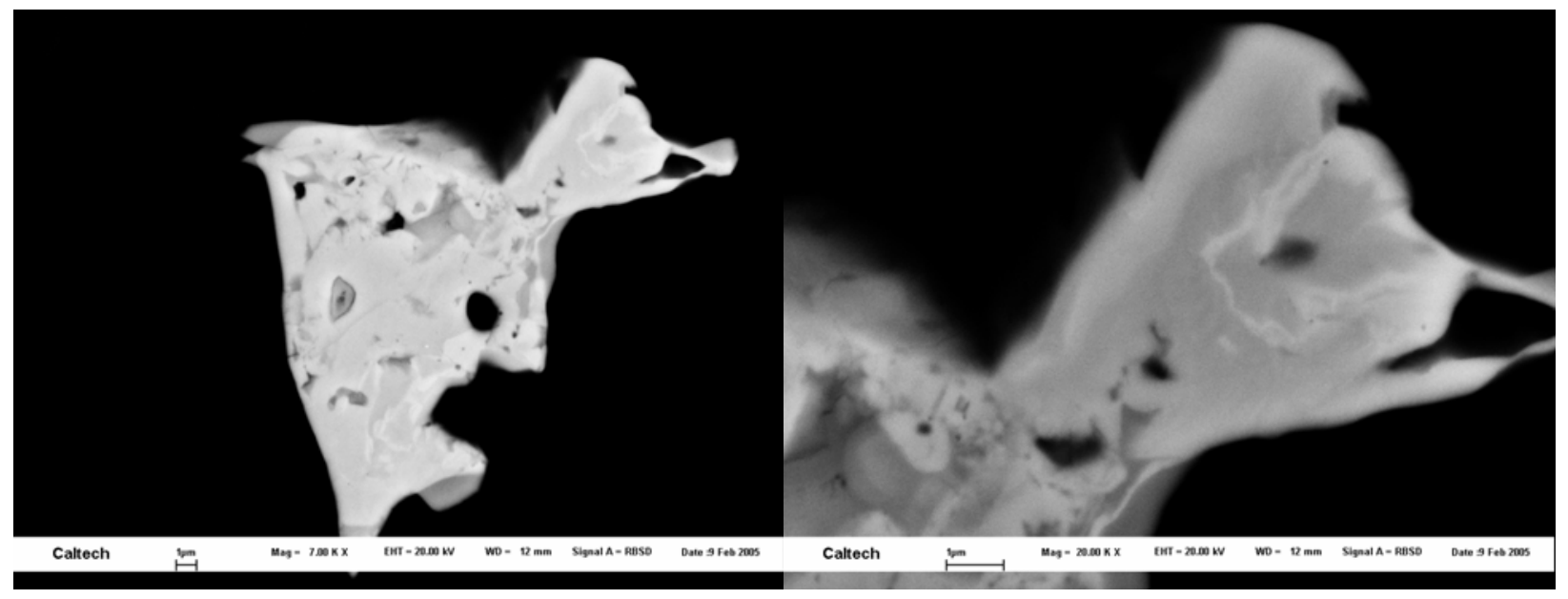

FIG. 1. BSE images of a hafnian zircon crystal revealing irregular zoning.

(a)

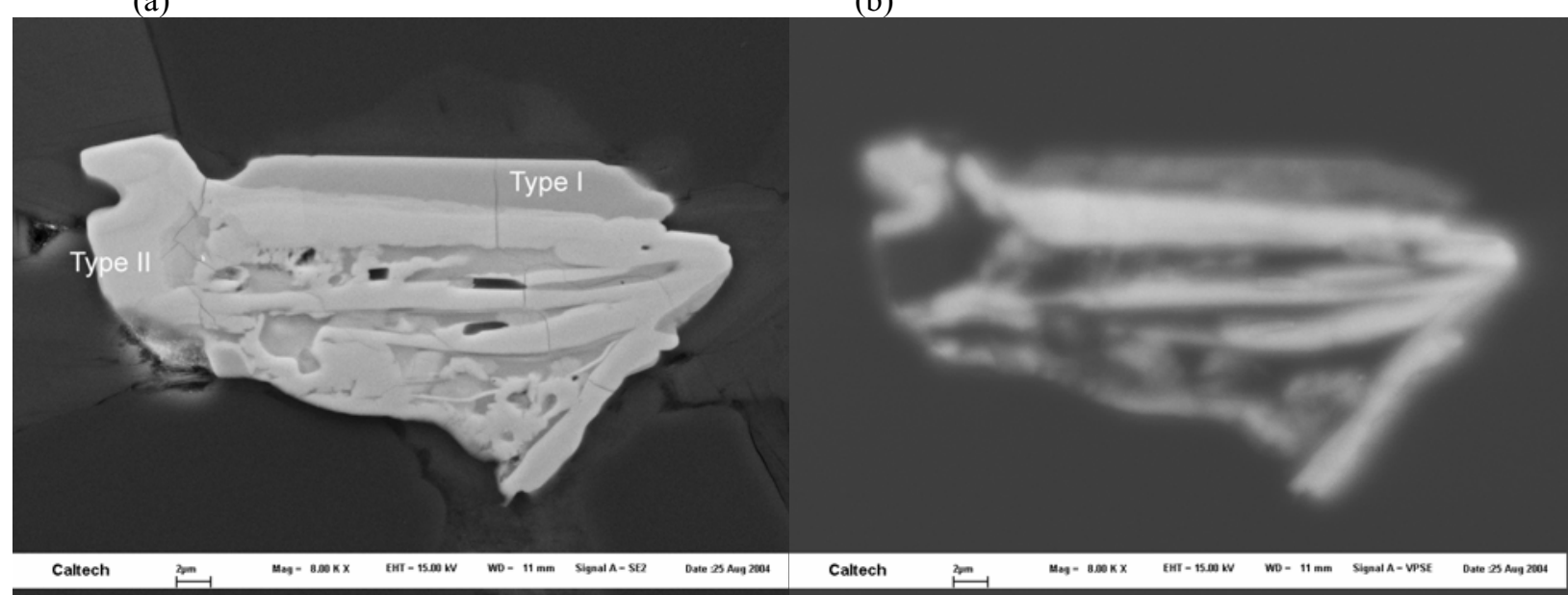

(c)

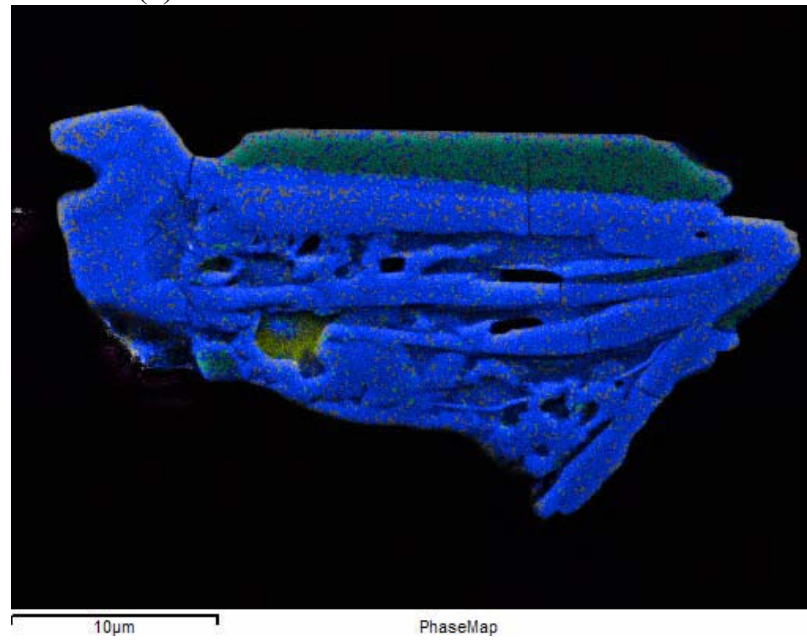

(d)

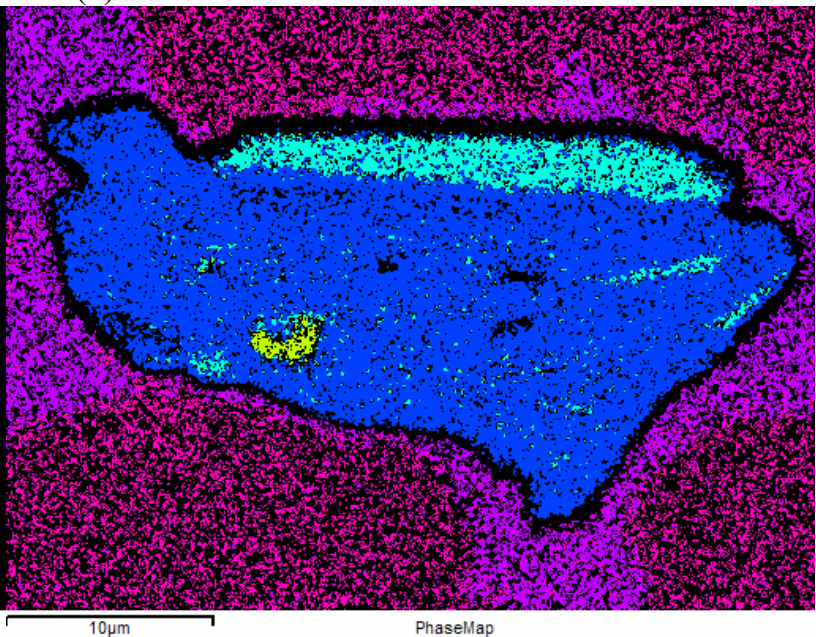

FIG. 2. A typical hafnian zircon crystal. (a) BSE image, (b) CL image, (c) phase map with BSE image as background, and (d) phase map without background. Blue - hafnian zircon ( $\mathrm{Hf} / \mathrm{Zr}=0.7 \sim 1)$; Cyan - Type I overgrowth $(\mathrm{Hf} / \mathrm{Zr}=0.1)$; Yellow - a brabantite inclusion; Pink - lepidolite; Magenta - elbaite. 